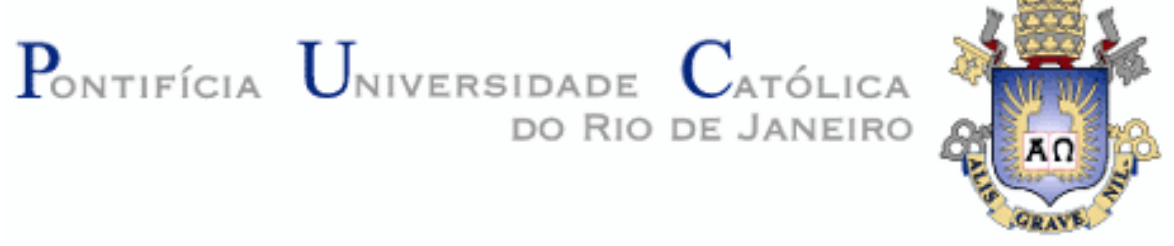

Fernanda Primo de Mendonça

\title{
A Relação Entre Risco Idiossincrático e Retorno no Mercado
}

Acionário Brasileiro

\section{Dissertação de Mestrado}

Dissertação apresentada ao Programa de Pósgraduação em Administração de Empresas da PUC-Rio como requisito parcial para obtenção do titulo de Mestre em Administração de Empresas.

Orientador: Prof. Marcelo Cabus Klotzle 
Fernanda Primo de Mendonça

\title{
A Relação Entre Risco Idiossincrático e Retorno no Mercado Acionário Brasileiro
}

\begin{abstract}
Dissertação apresentada como requisito parcial para obtenção do grau de Mestre pelo Programa de Pósgraduação em Administração de Empresas da PUC-Rio. Aprovada pela Comissão Examinadora abaixo assinada.

Prof. Marcelo Cabus Klotzle

Orientador Departamento de Administração - PUC-Rio
\end{abstract}

Prof. Antonio Carlos Figueiredo Pinto Departamento de Administração - PUC-Rio

Prof. Roberto Marcos da Silva Montezano IBMEC

Profa. Mônica Herz Vice-Decana de Pós-Graduação do CCS

Rio de Janeiro, 14 de junho de 2011 
Todos os direitos reservados. É proibida a reprodução total ou parcial do trabalho sem a autorização da universidade, da autora e do orientador.

Fernanda Primo de Mendonça

Graduou-se em Ciências Econômicas na PUC-Rio em 2007. Concluiu o curso de International Management no IAEUniversité Pierre Mendès em Grenoble, França em 2010.

Mendonça, Fernanda Primo de

A relação entre risco idiossincrático e retorno no mercado acionário brasileiro / Fernanda Primo de Mendonça ; orientador: Marcelo Cabus Klotzle. - 2011.

$57 \mathrm{f}$; $30 \mathrm{~cm}$

Dissertação (mestrado) - Pontifícia Universidade Católica do Rio de Janeiro, Departamento de Administração, 2011. Inclui bibliografia

1. Administração - Teses. 2. Risco idiossincrático. 3. Mercado acionário. 4. Retorno. 5. Modelo EGARCH. 6. Modelo de três fatores. I. Klotzle, Marcelo Cabus. II. Pontifícia Universidade Católica do Rio de Janeiro. Departamento de Administração. III. Título. 


\section{Agradecimentos}

Ao meu orientador Professor Marcelo Cabus Klotzle, pelo apoio e estímulo durante todo o curso e pela parceria para a realização deste trabalho.

Ao Professor Antonio Carlos Figueiredo Pinto, pelas importantes contribuições e por ter despertado em mim o interesse no tema.

Ao CNPq, à Faperj e à PUC-Rio, pelos auxílios concedidos, sem os quais este trabalho não poderia ter sido realizado.

Aos meus pais, pela minha educação, por todo o carinho e por sempre terem acreditado em mim.

Aos meus avós, por terem comemorado comigo cada conquista.

Aos meus amigos da PUC-Rio.

A todos os professores e funcionários do Departamento pelos ensinamentos e pela ajuda. 


\section{Resumo}

Mendonça, Fernanda Primo de; Klotzle, Marcelo Cabus. A relação entre risco idiossincrático e retorno no mercado acionário brasileiro. Rio de Janeiro, 2011. 57p. Dissertação de Mestrado - Departamento de Administração, Pontifícia Universidade Católica do Rio de Janeiro.

A relação entre risco idiossincrático e o retorno já foi amplamente estudada em diversas publicações internacionais, contudo, os resultados encontrados são controversos. Para o caso brasileiro, estudos sobre este tema são ainda escassos. Este trabalho procura verificar a relação entre o risco idiossincrático e o retorno das ações no mercado brasileiro. Para isso, utilizou-se dois métodos para estimação da volatilidade idiossincrática: um através dos resíduos de regressões baseadas no Modelo de Três Fatores de Fama e French, e o outro através do modelo EGARCH, que forneceu a volatilidade condicional. As variáveis encontradas foram adicionadas a modelos de regressões cross-section, juntamente com outras variáveis específicas às ações, a saber: beta, valor de mercado, índice book-to-market, efeito momentum e liquidez. Os resultados mostram que a volatilidade idiossincrática apresenta influência positiva e significante sobre o retorno, e que o modelo de explicação mais apropriado é o que inclui todas as variáveis citadas, utilizando como variável de volatilidade idiossincrática a estimada segundo o primeiro método citado.

\section{Palavras-chave}

Risco Idiossincrático; Mercado Acionário; Retorno; Modelo EGARCH; Modelo de Três Fatores. 


\begin{abstract}
Mendonça, Fernanda Primo de; Klotzle, Marcelo Cabus (Advisor). The relationship between idiosyncratic risk and stock returns in the Brazilian stock market. Rio de Janeiro, 2011. 57p. MSc. Dissertation - Departamento de Administração, Pontifícia Universidade Católica do Rio de Janeiro.
\end{abstract}

The relationship between idiosyncratic risk and stock returns has been widely studied in various international publications, however, the results are controversial. For the Brazilian case, studies on this subject are still scarce. This work seeks to verify the relationship between idiosyncratic risk and stock returns in the Brazilian stock market. To achieve this goal, two methods to estimating the idiosyncratic volatility were used: one through the residuals of regressions based on the Fama and French Three-Factor Model, and the other one through the EGARCH model, which provided the conditional volatility. These variables were added to cross-section regression models, along with other stock-specific variables, namely: beta, market value, book-to-market ratio, momentum effect and liquidity. The results show that idiosyncratic volatility has positive and significant influence on stock returns, and that the most appropriate model is the one that includes all the mentioned variables.

\title{
Keywords
}

Idiosyncratic Risk; Stock Market; Stock Returns; EGARCH Model; ThreeFactor Model. 


\section{Sumário}

1. Introdução 9

1.1. Contexto 9

1.2. A Pesquisa 10

1.3. Relevância 11

1.4. Delimitações 12

1.5. Descrição dos Capítulos 12

2. Referencial Teórico 14

2.1. A Análise do Retorno 14

2.2. O Risco Idiossincrático 19

3. Metodologia 23

3.1. Estimação da Volatilidade Idiossincrática Através do
Modelo de Fama \& French (VI)

3.2. Propriedades das Séries Temporais de Volatilidade
Idiossincrática (VI)

3.3. Os Modelos ARCH 29

3.4. Estimação da Volatilidade Idiossincrática Através do
Modelo EGARCH $(\mathrm{E}(\mathrm{VI}))$

3.5. Demais Variáveis a Serem Incluídas nas Regressões
Cross-Section

4. Resultados 38

4.1. Correlações 38

4.2. Regressões Cross-Section 42

5. Conclusão 52

6. Bibliografia $\quad 54$ 


\section{Lista de tabelas}

Tabela 3.1 - Estatísticas das séries de volatilidade idiossincrática individuais (\% mensal)

Tabela 3.2 - Teste de passeio aleatório para as séries de volatilidade idiossincrática (VI)

Tabela 3.3 - Estatísticas das séries de volatilidade idiossincrática condicional individuais (\% mensal)

Tabela 3.4 - Estatísticas descritivas das variáveis (pooled sample)

Tabela 4.1 - Médias das correlações cross-section entre as variáveis

Tabela 4.2 - Modelos de regressões cross-section:

regressões dos retornos contra a volatilidade idiossincrática

e outras variáveis específicas 